Article

\title{
The Application of Alginate Coated Iron Hydroxide for the Removal of Cu(II) and Phosphate
}

\author{
Hee-Gon Kim ${ }^{1}$, Feng $\mathrm{He}^{2}$ and Byungryul An ${ }^{3, *}$ \\ 1 Water Cycle Research Center, Korea Institute of Science and Technology, Seoul 02792, Korea; \\ 090923@kist.re.kr \\ 2 College of Environment, Zhejiang University of Technology, Hangzhou 310014, China; fenghe@zjut.edu.cn \\ 3 Department of Civil Engineering, Sangmyung University, Cheonan 31066, Korea \\ * Correspondence: bran@smu.ac.kr
}

Received: 19 August 2019; Accepted: 6 September 2019; Published: 12 September 2019

\begin{abstract}
The removal of both cation and anion contaminants in solution typically requires separate processes or multiple materials, resulting in added complexity and higher operational costs. A cost effective and environmental friendly hybrid adsorbent material has been developed for the removal of $\mathrm{Cu}(\mathrm{II})$ and phosphate from the solution. Ferric hydroxide (FHO) was prepared by precipitation methods and then dissolved alginate, a biopolymer, was coated on the surface of the FHO particles to generated FHO-A. In the preparation of FHO-A, the alginate concentration is a critical factor in keeping the FHO-A particles suspended in solution where high concentrations of alginate act as a stabilizer and the FHO-A particles are not settled by gravity. The $\mathrm{Cu}(\mathrm{II})$ removal efficiency was wholly dependent on the concentration of alginate via the interaction with the polymer carboxyl groups and was not influenced by the concentration of FHO. Conversely, alginate was not involved in the removal of phosphate and instead, FHO was found to be critical for phosphate removal through electrostatic forces. According to FTIR, the new peaks at 1394 and $1593 \mathrm{~cm}^{-1}$ after coating indicated that the alginate was appended to the surface of the FHO. The shift of peak from 1593 to $1588 \mathrm{~cm}^{-1}$ after $\mathrm{Cu}(\mathrm{II})$ adsorption confirms the presence of a $\mathrm{Cu}$-carboxylate interaction. The adsorption of $\mathrm{Cu}$ (II) was completed within $5 \mathrm{~min}$, which is very similar to nanoparticle mediated sorption processes. In comparison to $\mathrm{Cu}(\mathrm{II})$, the presence of alginate retards the phosphate removal rate. Further, $\mathrm{pH}$ dependence was observed in the process, where increasing $\mathrm{pH}$ results in increased $\mathrm{Cu}$ (II) and decreased phosphate removal rates due to alginate deprotonation and the surface charge effects, respectively. The slowed phosphate sorption rate and shifted peaks in the FTIR spectrum confirmed that the layer of alginate was coated on the FHO particle.
\end{abstract}

Keywords: $\mathrm{FHO}$; alginate; adsorption; $\mathrm{Cu}(\mathrm{II})$; phosphate

\section{Introduction}

The effluent produced by industrial or technological activity may contain high concentrations of heavy metals and the efficient treatment of these waste streams is of critical importance due to, in part, their toxic nature and, persistence in environment stemming from a lack of biodegradation pathways [1]. The release of $\mathrm{Cu}$ (II) has typically been the result of industrial activities such as electronics plating, wire drawing, copper polishing and so on, increasing the possibility to discharge copper into the water body [2]. In terms of human impact, the excessive ingestion of copper results in nausea vomiting and stomach cramps [3].

In general, the various technologies, such as biodegradation, photocatalysis, chemical precipitation, ion exchange, adsorption, filtration, reverse osmosis, have been developed and employed to eliminate heavy metal from water or wastewater [4]. Among them, chemical precipitation (CP), cation ion 
exchange (CIX) and adsorption were common technologies for $\mathrm{Cu}(\mathrm{II})$ removal [5-7]. Although each technology has advantages and disadvantages. The $\mathrm{CP}$ showed economic feasibility but huge sludge generation and CIX obtained high removal at a wide range solution $\mathrm{pH}$ but it required regeneration [8]. Adsorption is currently regarded as one of the most effective technologies for industrial wastewater treatment with a flexible design, ease of operation and effluent acceptable for release [9]. For example, activate carbon (AC) used in the granulated (GAC) or powdered (PAC) form, or iron-based oxides have been continuously studied due to their high sorption capacity and easy application in the field. However, they were only employed for the removal of anionic pollutants such as arsenic, phosphate and some organic matter in water and wastewater treatment. Alternatively, bio(ad)sorption has been recognized as a very promising process to remove heavy metals utilizing natural biopolymers, such as algae [10], alginate [2], chitin/chitosan, seaweed, and yeasts. This alternative sorption process offers substantial benefits including reduced toxicity of the materials, cost-effectiveness and high capacity [2]. Among them, alginate has been proved in heavy metal removal obtaining the high sorption capacity for $\mathrm{Cu}(\mathrm{II})$, chemical stability, and hydrophilicity [11,12].

Alginate extracted from brown algae is a heteropolymer consisting of 1-4 linked $\alpha$-L-guluronic and $\beta$-D-mannuronic acids [13]. The presence of carboxylic groups, naturally occurring in each constituent residue, showed high affinity for divalent cations, inducing complexation. Based on the acid-base and solubility properties, alginate has been employed to generate a variety of hydrogels after calcium (Ca(II)) crosslinking.

Iron hydroxide or iron oxide, including granular iron hydroxide, has been widely applied in water/wastewater treatment to remove phosphate [14], arsenic [15], and $\mathrm{Cr}(\mathrm{VI})$ [16], which are present in an anionic form. The adsorption capacity of these materials is determined by the particle size, surface area, or pore volume. However, in order to be applied in the removal of cationic contaminants, the chemical modification of the surface is required. The methods, such as grafting [17] or coating [18] of inorganic materials, have shown to be effective in generating materials with increased selective sorption properties for cations but do so at the expense of the anion capacity due to the blockage of the sorption sites and/or pore volume. The layer of alginate on the surface of ferric hydroxide (FHO) can improve the cation sorption capacity by conducting the complex between $\mathrm{Cu}(\mathrm{II})$ and carboxyl groups. As result, the hybrid adsorbent (natural organic and inorganic mixed adsorbent) was used for arsenic removal using cellulose with iron oxyhydroxide [18] and iron oxide loaded alginate beads [19]. In principle, $\mathrm{FHO}$ has been applied for the removal of anions from the solution by the electrostatic interaction. To determine the negative effects of anion removal, phosphate was also compared as a nutrient which causes eutrophication in water bodies in spite of a very low concentration [20].

The overall objective of the present study is to investigate $\mathrm{Cu}(\mathrm{II})$ removal using FHO-A under a variety of experimental conditions. Specifically, the goals are to: (1) Determine the $\mathrm{Cu}$ (II) removal capacity of FHO-A as well as phosphate; (2) determine the adsorption behavior using an isotherm test and kinetics studies; and (3) explore the $\mathrm{pH}$ effects.

\section{Material and Methods}

\subsection{Chemicals}

Sodium alginate flakes (M.W.: 155,000), ferric chloride $\left(\mathrm{FeCl}_{3}\right), \mathrm{KH}_{2} \mathrm{PO}_{4}, \mathrm{HCl}$ and $\mathrm{NaOH}$ were purchased from Sigma-Aldrich (Saint Louis, MO, USA). $\mathrm{CuCl}_{2} \cdot 2 \mathrm{H}_{2} \mathrm{O}$ was purchased from SHOWA (Tokyo, Japan). All are ACS grade, and the chemical was used without further purification.

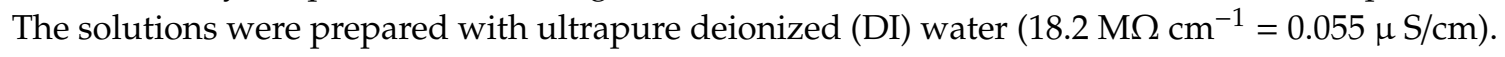

\subsection{Synthesis of Alginate Coated Iron Hydroxide}

The FHO was prepared by the co-precipitation method in the presence of a desired concentration of alginate. Initially, a $1 \mathrm{wt} . \%$ alginate stock solution was prepared by dissolving $2 \mathrm{~g}$ sodium alginate flakes in $198 \mathrm{~mL}$ DI water and stirring at room temperature for $24 \mathrm{~h}$. To prepare $\mathrm{FHO}, 2 \mathrm{mM}$ of $\mathrm{FeCl}_{3}$ 
solution was first dissolved for at least $24 \mathrm{~h}$ at room temperature. A desired volume of alginate was added into the $2 \mathrm{mM} \mathrm{FeCl}_{3}$ solution for at least $1 \mathrm{~h}$ with rapid mixing. The $\mathrm{pH}$ mixture increased to $7.0 \pm 0.3$ using $\mathrm{NaOH}$ and then was mixed for further $1 \mathrm{~h}$ at a reduced stirring rate. To age the FHO particle, the mixture was allowed to stand for $24 \mathrm{~h}$. The FHO-A particle or suspension was formed depending on the amount of alginate solution and was stored in the liquid phase before use.

\subsection{FTIR Analysis}

Fourier transform infrared spectroscopy (FTIR) was performed using a Spotlight 200 spectrophotometer (PerkinElmer, Waltham, MA, USA). The spectra of the representative samples of FHO, FHO-A, and sorption of $\mathrm{Cu}$ (II) or phosphate for $\mathrm{FHO}$ was obtained over the wave number range from 400 to $4000 \mathrm{~cm}^{-1}$.

\subsection{Bath Equilibrium Test}

To determine the removal efficiency of $\mathrm{Cu}(\mathrm{II})$ and phosphate, a series of batch tests were carried out using $55 \mathrm{~mL}$ of conical tubes. The stock solutions of $\mathrm{Cu}$ (II) $(2000 \mathrm{mg} / \mathrm{L})$ and phosphate $(2000 \mathrm{mg} / \mathrm{L})$ were prepared with $\mathrm{CuCl}_{2} \cdot 2 \mathrm{H}_{2} \mathrm{O}$ and $\mathrm{KHPO}_{4}$, respectively. The initial concentration of $\mathrm{Cu}(\mathrm{II})$ and phosphate was set to $5 \mathrm{mg} / \mathrm{L}$. The different concentrations of Fe were prepared by adding a desired volume of FHO-A solution, and then a desired volume of $\mathrm{Cu}(\mathrm{II})$ and phosphate from the stock solution was added. The conical tubes were rotated at $30 \mathrm{rpm}$ for $24 \mathrm{~h}$ without $\mathrm{pH}$ adjustment. Similar batch tests were conducted except for controlling for $\mathrm{pH}$ during the experiment. The initial $\mathrm{pH}$ of mixture was set to $3,4,5,6,7$, and 9 and during rotation, $0.1 \mathrm{NaOH}$ or $0.1 \mathrm{HCl}$ was added at intermittent intervals.

To determine the $\mathrm{Cu}(\mathrm{II})$ and phosphate removal uptake, a series of batch equilibrium tests were carried out for $\mathrm{Cu}(\mathrm{II})$ and phosphate following a similar procedure. The following conditions were initiated: The initial concentration of $\mathrm{Cu}$ (II) and phosphate were 10 and $15 \mathrm{mg} / \mathrm{L}$, the Fe concentration as Fe was at 1.0 and $2.0 \mathrm{mM}$. The Langmuir and Freundlich equilibrium model were applied to find the sorption process. Each data was fitted band calculated by a sigma plot program.

\subsection{Kinetic Tests}

To estimate the rate of $\mathrm{Cu}(\mathrm{II})$ and phosphate sorption on FHO-A, the batch kinetic tests were conducted. First, FHO-A $(500 \mathrm{~mL})$ was prepared and then a sorption test was initiated by individually adding $\mathrm{Cu}(\mathrm{II})$ and phosphate to give the following initial concentrations: $\mathrm{Fe}=2.0 \mathrm{mM}, \mathrm{Cu}(\mathrm{II})=10 \mathrm{mg} / \mathrm{L}$, and phosphate $=15 \mathrm{mg} / \mathrm{L}$. Each sample was taken out at 5, 10, 30, 60, 180, and $360 \mathrm{~min}$. The initial pH was adjusted to 5.0 and the $\mathrm{pH}$ was measured but not adjusted during the experiment.

Pseudo 1st and 2nd order models were used to describe the initial state of adsorption and anticipate the adsorption behavior through the whole range, respectively [21]. Each parameter was calculated by fitting with the experimental data.

\subsection{Instrumental Techniques}

Further, $5-10 \mathrm{~mL}$ of supernatant from each sample was taken out and then filtered by PVDF $0.45 \mu \mathrm{m}$ filter (GVS syringe filter, Genomed, Daejeon, Korea). The concentration of copper and phosphate was analyzed in the form of $\mathrm{Cu}$ (II) and phosphorus, respectively, using inductively coupled plasma (ICP) spectroscopy (Model: NexION 300D, Agilent Technologies, Santa Clara, CA, USA) which has a detection limit of $20 \mu \mathrm{g} / \mathrm{L}$. A Laboratory VIS Spectrophotometer (Model: DR 3900, HACH, Loveland, CO, USA) for $\mathrm{Cu}$ (II) and portable analyzer (Model: HS-1000plus, HUMAS, Daejeon, Korea) for phosphorus were also used which have a detection limit of $250 \mu \mathrm{g} / \mathrm{L}$ and $10 \mu \mathrm{g} / \mathrm{L}$, respectively. The ORION Star A211 pH meter (Thermo Scientific, Waltham, MA, USA) was used to measure the $\mathrm{pH}$ in solution. The amount of alginate dissolved in solution or coated on FHO was measured by a total organic carbon (TOC) analyzer (Shimadzu TOC-V analyzer) equipped with an ASI-5000A auto-sampler. Fourier transform infrared spectroscopy (FTIR) was applied to find the formation of alginate, iron, and $\mathrm{Cu}(\mathrm{II})$ and phosphate (model: spotlight 200, PerkinElmer, USA). 


\section{Results and Discussion}

\subsection{FHO-A}

To determine the impact of the concentration of alginate in solution on FHO-A synthesis, the concentration of alginate as TOC was measured and the amount of alginate as mass $(\mathrm{g})$ was calculated before and after synthesis of FHO-A. Table 1 shows the amount or concentration of alginate when added at 60,120 , and $180 \mathrm{mg} / \mathrm{L}$. The difference between alginate concentrations before and after synthesis can be considered to be total amount of coated alginate on FHO. After synthesis of FHO-A, the concentration of alginate was $5.4,4.16$, and $38.2 \mathrm{mg} / \mathrm{L}$ for A-60, A-120, and A-180, namely $91.0 \%$, $96.5 \%$, and $78.6 \%$ of initial alginate were used in synthesis, respectively. As such, the highest coating efficiency was accomplished at A-120, while the highest alginate concentration was obtained on A-180. Ideally, the conditions were used to generate $\mathrm{A}-180$ provide maximum $\mathrm{Cu}(\mathrm{II})$ removal, but in practice, the excess alginate concentration in solution required a longer solid-liquid separation time due to the increase in viscosity and the suspension of FHO-A particles. Biopolymers, such as starch, have been utilized as stabilizers [22]. Therefore, the following experiment was carried out using FHO-A prepared with A-120 except for the batch removal efficiency tests.

Table 1. Concentration of alginate before and after ferric hydroxide-alginate (FHO-A) synthesis.

\begin{tabular}{|c|c|c|c|}
\hline & $\mathrm{A}-60 \mathrm{mg} / \mathrm{L}$ & A-120 mg/L & $\mathrm{A}-180 \mathrm{mg} / \mathrm{L}$ \\
\hline Initial alginate concentration in solution, $\mathrm{mg} / \mathrm{L}$ & 60 & 120 & 180 \\
\hline Final alginate concentration in solution, $\mathrm{mg} / \mathrm{L}$ & 5.40 & 4.16 & 38.2 \\
\hline Unused alginate, $\%$ & 9.00 & 3.47 & 21.4 \\
\hline Amount of alginate on $\mathrm{FHO}, \mathrm{mg}$ & 27.3 & 57.9 & 70.7 \\
\hline
\end{tabular}

The stability of FHO-A was also considered by measuring the concentration of Fe and alginate in solution. The concentration of Fe in a form Fe(III) was ignorable even in the acid condition, indicating that the particle of HFO-A was stable due to the interaction between Fe(III) and the carboxyl group of alginate.

\subsection{FTIR}

Figure 1 shows the FTIR spectra for alginate, FHO, and FHO-A before and after the sorption of $\mathrm{Cu}$ (II) or phosphate. In Figure 1a, the broad peak from $3500 \sim 3000 \mathrm{~cm}^{-1}$ represents the $\mathrm{H}-\mathrm{O}$ stretching bond from $\mathrm{H}_{2} \mathrm{O}$ [23]. The peaks at 426 and $743 \mathrm{~cm}^{-1}$ appeared only for $\mathrm{FHO}$, which was assigned to the Fe-O-Fe stretching vibration [24] and would be the Fe-OH band, respectively [25]. A peak at $1021 \mathrm{~cm}^{-1}$ was detected for alginate, FHO, and FHO-A which can be assigned to O-H bending [26]. Compared with FHO, some small peaks at 1522 and $1631 \mathrm{~cm}^{-1}$ were not apparent for FHO-A, instead, two new peaks appeared at 1398 and $1593 \mathrm{~cm}^{-1}$ for FHO-A which were also shown in the alginate spectra. In general, the peaks ranging from $1400 \sim 1600 \mathrm{~cm}^{-1}$ represent the O-C-O stretching bond [27] and then the peak at 1409 and $1585 \mathrm{~cm}^{-1}$ are the symmetrical and asymmetrical stretching C-O of the carboxylate group from alginate [28]. Therefore, there is evidence that the alginate polymer was firmly coated on the FHO.

Figure $1 \mathrm{~b}$ compared FTIR data after the adsorption for $\mathrm{Cu}(\mathrm{II})$ and phosphate for FHO and FHO-A. The peak at 426 and $743 \mathrm{~cm}^{-1}$ was still detected after both $\mathrm{Cu}(\mathrm{II})$ and phosphate adsorption for FHO-A. The peak of $1582 \mathrm{~cm}^{-1}$ shifted from $1593 \mathrm{~cm}^{-1}$ (Figure 1a) and observed for FHO-A-C and FHO-A-P. The slightly declined peak at $1593 \mathrm{~cm}^{-1}$ to $1588 \mathrm{~cm}^{-1}$ was also observed by Papageorgiou et al. [29] and was due to the formation of a $\mathrm{Cu}$-carboxylate complex. It is obvious that the metal-carboxylate complex (M-O) coordinates in the bidentate chelating form [30,31]. However, the $\mathrm{Cu}$-ligand chelating interaction may happen with weaker intensity for phosphate than for carboxylate, even though phosphate was negatively charged in the solution. For FHO without alginate, the peak after $\mathrm{Cu}$ (II) or phosphate 
adsorption decreased from $1582 \mathrm{~cm}^{-1}$ to $1567 \mathrm{~cm}^{-1}$ or increased from 1582 to $1634 \mathrm{~cm}^{-1}$, respectively, indicating that there were other interactions occurring. Namely, phosphate ions and iron oxide are implied to form inner-sphere surface complexes [32-34].
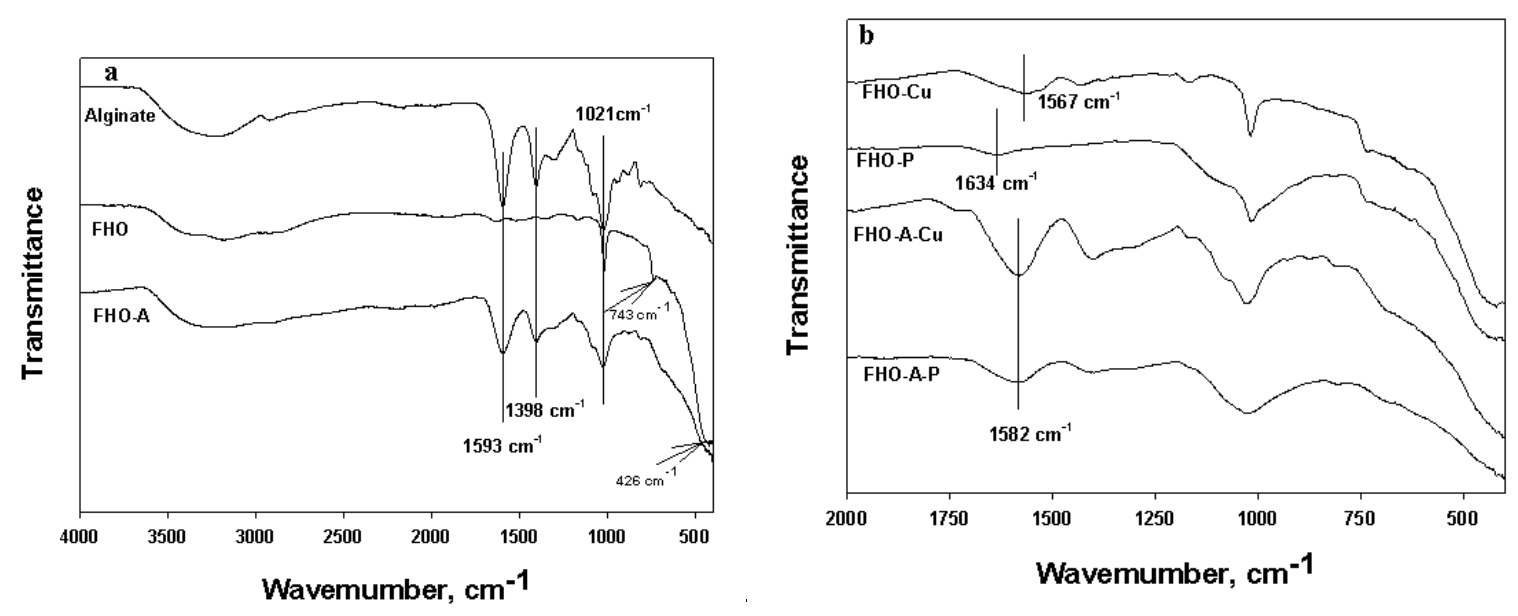

Figure 1. FTIR spectra for (a) alginate, bare $\mathrm{FHO}$ and $\mathrm{FHO}-\mathrm{A}$ and (b) after $\mathrm{Cu}(\mathrm{II})$ and phosphate adsorption for $\mathrm{FHO}$ and $\mathrm{FHO}-\mathrm{A}$.

\section{3. $\mathrm{Cu}(I I)$ and Phosphate Removal Efficiency}

To determine the capability of $\mathrm{FHO}$ and the effect of alginate for the removal of $\mathrm{Cu}(\mathrm{II})$ as well as phosphate, a variety of batch tests were conducted at different concentrations of Fe and alginate on FHO. Figure 2a shows the removal efficiency of $\mathrm{Cu}(\mathrm{II})$ and phosphate for bare FHO and FHO-A at a concentration of 1.0 and $2.0 \mathrm{mM}$ of Fe. For $\mathrm{Cu}$ (II) removal, FHO was shown to remove only $2 \sim 3 \%$ of $\mathrm{Cu}$ (II) at both tested Fe concentrations, whereas FHO-A showed $\sim 40 \% \mathrm{Cu}$ (II) removal efficiency in the same $\mathrm{Fe}$ concentration range, indicating that $\mathrm{Cu}$ (II) removal was not affected by the presence of Fe. As such, these results show that $\mathrm{Cu}$ (II) removal is dependent only on the presence of alginate in these systems. Completely different results were shown for phosphate. The increased concentration of Fe from 1.0 and $2.0 \mathrm{mM}$ increased the phosphate removal efficiency from 40 to $60 \%$ and the effect of alginate was negligible. Therefore, it can be concluded that $\mathrm{Cu}(\mathrm{II})$ and phosphate removal occurred only due to the presence of alginate and $\mathrm{Fe}$, respectively. Figure $2 \mathrm{~b}$ shows the impact of different alginate concentrations added on FHO. The removal of phosphate was consistent, regardless of the concentration of alginate, indicating that the presence of alginate on FHO does not affect phosphate removal by $\mathrm{FHO}$, whereas the efficiency of $\mathrm{Cu}(\mathrm{II})$ increased from $\sim 4 \%$ up to $\sim 55 \%$ in the presence of increased alginate levels. Based on these results, $\mathrm{FHO}$ and alginate act independently from each other for cation and anion removal. Based on these findings, the mechanism detailed in Figure 3 which shows the electrostatic force between the carboxyl group of alginate and $\mathrm{Cu}(\mathrm{II})$, the surface charge of $\mathrm{FHO}$ and phosphate is proposed to account for $\mathrm{Cu}(\mathrm{II})$ and phosphate removal on $\mathrm{FHO}-\mathrm{A}$. 


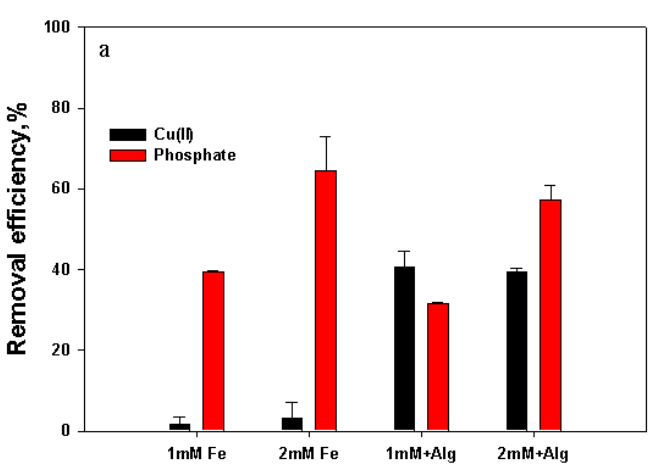

(a)

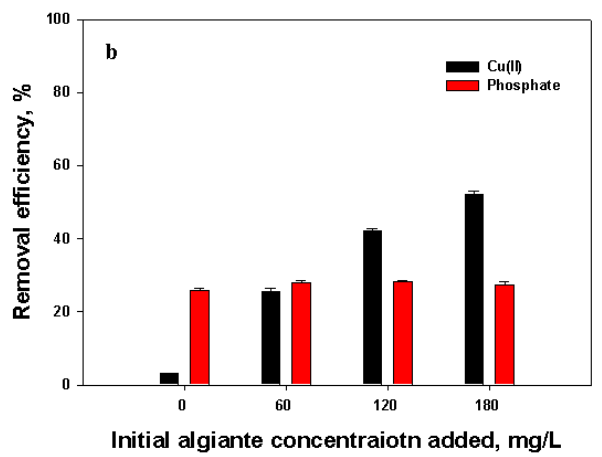

(b)

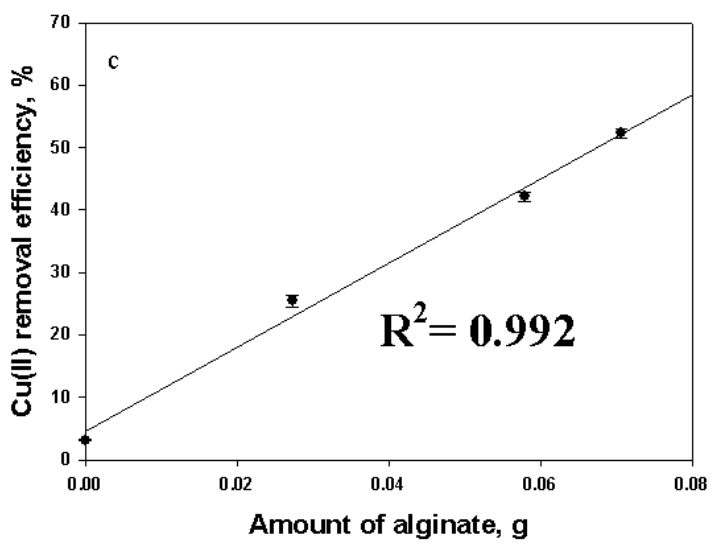

(c)

Figure 2. $\mathrm{Cu}(\mathrm{II})$ and phosphate removal efficiency (\%) at (a) different Fe concentrations (1 $\mathrm{mM}$ and $2 \mathrm{mM}$ ) and $120 \mathrm{mg} / \mathrm{L}$ of alginate solution, (b) different alginate concentrations (0, 60, 120, $180 \mathrm{mg} / \mathrm{L})$, and $(\mathrm{c})$ the relation between $\mathrm{Cu}(\mathrm{II})$ removal efficiency $(\%)$ and alginate amount $(\mathrm{g})$.
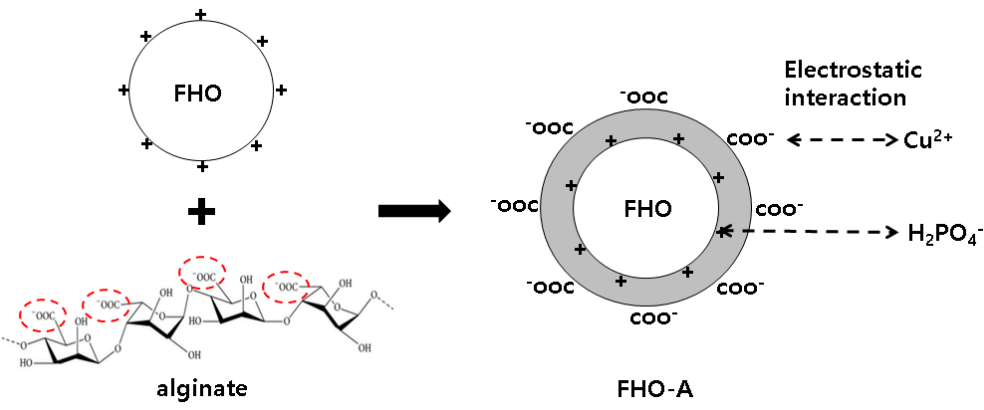

Figure 3. A schematic illustration of $\mathrm{Cu}(\mathrm{II})$ and phosphate removal on FHO-A.

A linear regression analysis of alginate concentration versus $\mathrm{Cu}(\mathrm{II})$ removal efficiency, shown in Figure 2c, clearly demonstrates a strong correlation between these factors $\left(R^{2}=0.992\right)$. Consequently, the direct and proportional removal of $\mathrm{Cu}$ (II) showed that only the alginate on the FHO-A was involved in $\mathrm{Cu}(\mathrm{II})$ adsorption.

\subsection{Kinetic Test}

Figure 4 shows $\mathrm{Cu}(\mathrm{II})$ and phosphate adsorption rates at $2 \mathrm{mM}$ of Fe. Initially, both contaminants show a rapid initial uptake, followed by a slower uptake that gradually reaches equilibrium due to the increased concentration gradient resulting in a high driving force from the solution to the surface. $\mathrm{Cu}$ (II) sorption equilibrium was achieved within $60 \mathrm{~min}$ and over $90 \%$ sorption was observed rapidly, 
requiring only a few minutes. The sorption rate is comparable with Mahmoodi [35] who obtained $\sim 90 \%$ of removal efficiency using the alginate solution within $10 \mathrm{~min}$, regardless of the initial amounts of alginate introduced. In comparison with the granule type alginate (average particle size of $3.5 \mathrm{~mm}$ ), a previous study required at least $24 \mathrm{~h}$ to reach the sorption equilibrium [2]. This indicates that the removal of $\mathrm{Cu}$ (II) is occurring on the surface of FHO-A and within the pore structures, as is observed in similar nanoparticle systems.

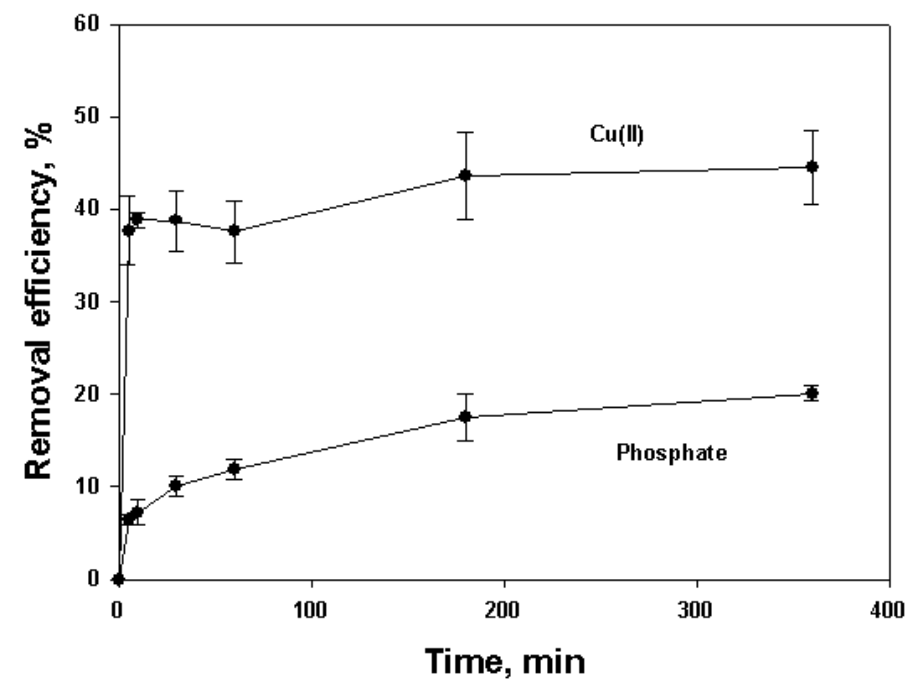

Figure 4. Kinetic test of FHO-A at $2 \mathrm{mM}$ Fe and $120 \mathrm{mg} / \mathrm{L}$ alginate.

The noted trends in phosphate removal are clearly different than $\mathrm{Cu}(\mathrm{II})$. Only $50 \%$ of phosphate was removed in $10 \mathrm{~min}$ and the removal efficiency gradually increased over the course of $6 \mathrm{~h}$. This is several times longer than previous studies using other iron-based adsorbents [36]. Pan et al. [37] prepared FHO on the pore of an anion exchange resin and reported that most phosphate can be removed within $60 \mathrm{~min}$. The use of powdered adsorbent (average size: 10-30 $\mu \mathrm{m}$ ) required less than $10 \mathrm{~min}$ to reach equilibrium, which was attributed to the same phenomena as the $\mathrm{Cu}$ (II) removal in our current study [38]. As suggested by the data presented in Figure 3 and Section 3.2, the longer equilibrium time for phosphate would be due phosphate penetrating the alginate polymer layer on the surface of FHO. In addition, the substantially faster kinetics for $\mathrm{Cu}$ (II) sorption supports the assertion that the alginate on the surface of $\mathrm{FHO}$ was responsible for the removal of $\mathrm{Cu}(\mathrm{II})$.

In order to clarify transient behavior of $\mathrm{Cu}(\mathrm{II})$ and phosphate, linearized forms for pseudo 1st and 2nd order models were used to fit the experiment data based on Equations (1) and (2), respectively:

$$
\begin{aligned}
& \ln \left(q_{e}-q_{t}\right)=\ln q_{e}-k_{1} t \\
& t / q_{t}=\left(\frac{1}{k_{2} q_{e}^{2}}\right)+\left(\frac{1}{q_{e}}\right) t
\end{aligned}
$$

where $q_{e}$ and $q_{t}$ are the uptake of the $\mathrm{Cu}(\mathrm{II})$ and phosphate per unit weight $(\mathrm{mg} / \mathrm{g})$ of $\mathrm{FHO}$ at equilibrium and at any time $(\mathrm{t})$, respectively, $k_{1}(1 / \mathrm{min})$ and $k_{2}(\mathrm{~g} / \mathrm{mg} \cdot \mathrm{min})$ are the rate constants of pseudo 1 st and 2nd sorption, respectively. The value of $k_{1}$ and $k_{2}$ can be used to obtain the slope and the intercept of linearized Equations (1) and (2), respectively.

Figure S1a,b shows the linearized pseudo 1st and 2nd order sorption model and the parameters used are found in Table 2. The results show that the pseudo 2nd order plot is a better fit to the data than pseudo 1st order, based on $\mathrm{R}^{2}$ values. Furthermore, the pseudo 1 st and pseudo 2 nd order plots exhibited a strong correlation between the calculated and experimental $q_{e}$ values for phosphate and $\mathrm{Cu}(\mathrm{II})$, respectively. A previous study [39] on metal removal using alginate confirmed that theoretical and experimental kinetics were well matched with a 2 nd order kinetic analysis. The fact 
that the 2nd order is more strongly correlated than the 1st order suggests that the rate-limiting step for $\mathrm{Cu}$ (II) adsorption on the FHO-A is chemical adsorption but not mass transport limitations $[40,41]$. In conjunction with this, the phosphate adsorption would be more affected by the mass transport due to the alginate layer.

The intraparticle diffusion model of Weber and Morris [42] is given in Equation (5).

$$
q_{t}=k_{3} t^{1 / 2}+C
$$

where, $k_{3}$ is the intraparticle diffusion rate constant $\left(\mathrm{mg} / \mathrm{g} \min ^{1 / 2}\right)$ and $C$ is the intercept $(\mathrm{mg} / \mathrm{g})$. A comparison of the intraparticle diffusion coefficient that was originally developed to determine the rate controlling step for pore diffusion can allow for the validation of the mechanism. From the data presented in Figure S1c and Table 2, the value of $k_{3}$ for phosphate was demonstrably higher than $\mathrm{Cu}$ (II) and in the plot. Both regression lines do not pass through the origin $(C \neq 0)$ and larger $R^{2}$ values are noted. The higher value of $k_{3}$ for phosphate signifies that the sorption process still continues through the alginate polymer layer on the surface played as porosity. The fact that the plotted lines did not pass through the origin implies that other mechanisms may be involved in the adsorption process along with intraparticle diffusion $[43,44]$.

Table 2. Pseudo 1st and 2nd order and intraparticle kinetic parameters.

\begin{tabular}{ccccccc}
\hline & & $\mathbf{k}$ & $\mathbf{R}^{\mathbf{2}}$ & $\mathbf{C}$ & q-exp. $^{(1)}$ & q-cal. $^{\text {(2) }}$ \\
\hline Pseudo & $\mathrm{Cu}(\mathrm{II})$ & 0.0174 & 0.926 & 3.29 & 26.8 & 84.8 \\
1st & Phosphate & 0.0169 & 0.962 & 3.88 & 48.4 & 48.6 \\
\hline Pseudo & $\mathrm{Cu}(\mathrm{II})$ & 0.0107 & 0.999 & 0.0378 & 93.5 & 84.8 \\
2nd & Phosphate & 0.0581 & 0.986 & 1.27 & 17.2 & 48.6 \\
\hline Intraparticle & $\mathrm{Cu}(\mathrm{II})$ & 0.9124 & 0.822 & 76.5 & - & - \\
& Phosphate & 2.1118 & 0.980 & 12.5 & - & - \\
\hline
\end{tabular}

(1) Experimental q value. (2) Calculated q value.

\subsection{Equilibrium Isotherm}

In general, a sorption equilibrium isotherm test can be utilized to optimize the design of an adsorption system for the removal of a target contaminant from the solution. Several types of isotherm equations were widely employed to predict the adsorption processes and behaviors, such as generalized, Temkin [45], Toth [46], Redlich-Peterson [47], Dubinin-Radushkevich [48] and two sorption equilibrium models, Langmuir [49] and Freundlich [50]. In principle, the Langmuir isotherm assumes that sorption takes place at a specific site and no further adsorption occurs after the sorption is complete, while the Freundlich isotherm occurs at infinite sorption on a heterogeneous surface through a multilayer.

The Langmuir and Freundlich equations are given in Equations (4) and (5), respectively, and both can be transformed to linear equations, as shown in Equations (6) and (7), respectively.

$$
\begin{gathered}
\text { Langmuir: } q_{e}=\frac{Q b C_{e}}{1+b C_{e}} \\
\text { Freundlich: } q_{e}=k_{f} C_{e}^{1 / n} \\
\text { Linear Langmuir: } \frac{C_{e}}{q_{e}}=\frac{1}{Q b}+\frac{1}{Q} C_{e} \\
\text { Linear Freundlich: } \ln q_{e}=\ln k_{f}+\frac{1}{n} \ln C_{e}
\end{gathered}
$$

where, $C_{e}$ is the equilibrium concentrations $(\mathrm{mg} / \mathrm{L})$ of $\mathrm{Cu}(\mathrm{II})$ or phosphate in solution and $q_{e}$ is the amount of $\mathrm{Cu}$ (II) or phosphate adsorbed per unit mass of FHO-A (mg/g), $Q$ is the maximum uptake 
per unit mass of FHO-A (mg/g), and $b$ is the Langmuir constant related to the adsorption energy $(\mathrm{L} / \mathrm{mg}), k_{f}$ is the Freundlich constant related to the adsorption capacity, $n$ is the empirical parameter representing the energetic heterogeneity of the adsorption sites (dimensionless). Therefore, the higher $\mathrm{b}$ and $k_{f}$ value represents higher affinity for adsorbate toward the adsorbent [41]. The value of $n$ from Freundlich can be utilized to differentiate between the alternate adsorption pathways, where $n>1$ is indicative of a physical process and $n<1$ is points to a chemical process [51].

Figure 5 showed the fitted adsorption isotherms and the calculated parameters are found in Table 3 . According to the values in Table 3, the parameters obtained by Langmuir for $\mathrm{Cu}$ (II) were not consistent and showed that no plateau was observed in Figure 5. This indicates that the sorption isotherm is not complete. The saturation of the sorbent is not achieved. In addition, the maximum uptake of $\mathrm{Cu}$ (II) was calculated to be 487 and $350 \mathrm{mg} / \mathrm{g}$ for the non-linear and linear equations, respectively. The correlation coefficients $\left(\mathrm{R}^{2}\right)$ of 0.966 and 0.704 , respectively, were noted and not comparable with other studies for the removal of $\mathrm{Cu}(\mathrm{II})$ [52]. This suggests that the Freundlich equation is more appropriate for fitting an isotherm profile for $\mathrm{Cu}$ (II). However, a comparison of the other model and the parameters for $\mathrm{Cu}$ (II) and phosphate can be done. Based on the values of $b, k_{f}$, and $n$, phosphate has a higher affinity and more favorable adsorption than $\mathrm{Cu}(\mathrm{II})$, verifying that the interaction between $\mathrm{FHO}$ and phosphate is stronger than that between alginate and $\mathrm{Cu}(\mathrm{II})$.

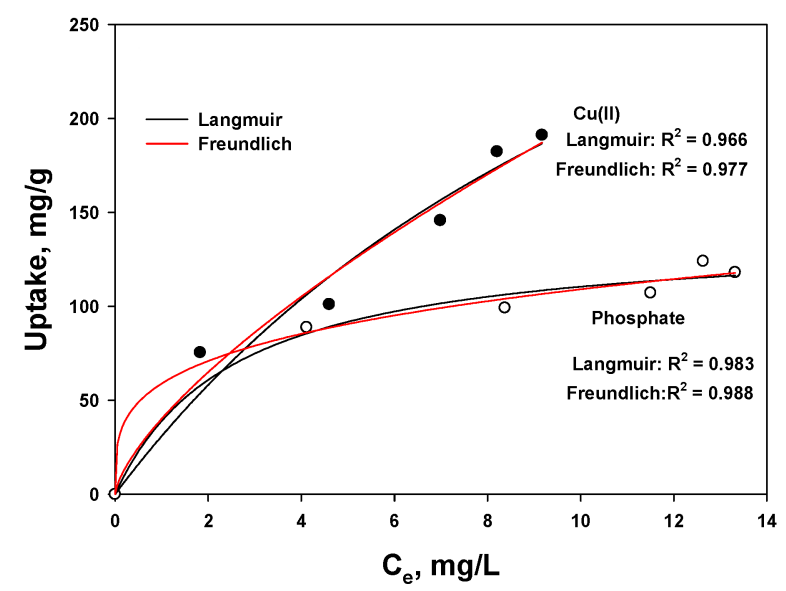

Figure 5. Plots for the non-linear Langmuir and Freundlich isotherm.

Table 3. Parameters of the Langmuir and Freundlich isotherm with non-linear and linear equations.

\begin{tabular}{cccccccc}
\hline & & \multicolumn{3}{c}{ Langmuir } & \multicolumn{3}{c}{ Freundlich } \\
\hline \multirow{2}{*}{$\mathrm{Cu}$} & $\mathbf{Q}$ & $\mathbf{b}$ & $\mathbf{R}^{\mathbf{2}}$ & $\mathbf{k}_{\mathbf{f}}$ & $\mathbf{n}$ & $\mathbf{R}^{\mathbf{2}}$ \\
\cline { 2 - 8 } & Non-linear & 487 & 0.0678 & 0.966 & 40.1 & 1.44 & 0.977 \\
\cline { 2 - 8 } Phosphate & Linear & 350 & 0.117 & 0.704 & 49.1 & 1.71 & 0.924 \\
\cline { 2 - 8 } & Non-linear & 139 & 0.3905 & 0.983 & 58.9 & 3.73 & 0.988 \\
\cline { 2 - 8 } & Linear & 136 & 0.401 & 0.986 & 62.6 & 4.28 & 0.944 \\
\hline
\end{tabular}

\section{6. $p H$ Effect}

The batch $\mathrm{pH}$ tests were conducted with the initial $\mathrm{pH}$ of the solutions ranging from 3 to 9 . The solution $\mathrm{pH}$ strongly influences the sorption capacity of the target contaminant by determining the distribution of the species or by acting as competitor ions in the form of hydronium or hydroxide at low or high $\mathrm{pH}$, respectively. Figure 6 a shows the $\mathrm{Cu}$ (II) and phosphate removal efficiency as a function of the initial solution $\mathrm{pH}$. FHO-A obtained $\sim 0,20$ and $40 \%$ removal efficiency at $\mathrm{pH}$ values of 3,4 , and 5, respectively, while $\mathrm{Cu}(\mathrm{II})$ was not removed by FHO below $\mathrm{pH} 5$, confirming that higher $\mathrm{pH}$ correlates with greater removal of $\mathrm{Cu}$ (II) with alginate on the surface of FHO-A. This is accordance 
with previous studies [2] which showed that the optimized solution $\mathrm{pH}$ for an alginate bead was reported to be $\sim 5$. This can be explained due to the $\mathrm{pK}_{\mathrm{a}}$ value of alginate, which is 3.38-3.65 depending on type of copolymers based on $\beta$-D-mannuronic acid (M) and $\alpha$-L-guluronic acid (G) [53]. Therefore, both deprotonation of alginate and the presence of hydronium ion compete with $\mathrm{Cu}(\mathrm{II})$ to interrupt the sorption at pH 3 (shown in Equations (8) and (9)). Note that the $\mathrm{Cu}(\mathrm{II})$ removal efficiency after $\mathrm{pH} 5$ is due to precipitation.

$$
\begin{aligned}
& \text { At } \mathrm{pH}>\mathrm{pka},(\mathrm{R}-\mathrm{COO})-\mathrm{H}^{+}+\mathrm{Cu}^{2+} \rightarrow(\mathrm{R}-\mathrm{COO})-\mathrm{Cu}^{2+}+\mathrm{H}^{+} \text {(reaction) } \\
& \mathrm{pH}<\mathrm{pka},(\mathrm{R}-\mathrm{COO})-\mathrm{H}^{+}+\mathrm{Cu}^{2+} \rightarrow(\mathrm{R}-\mathrm{COO})-\mathrm{H}^{+}+\mathrm{Cu}^{2+}(\text { no reaction })
\end{aligned}
$$
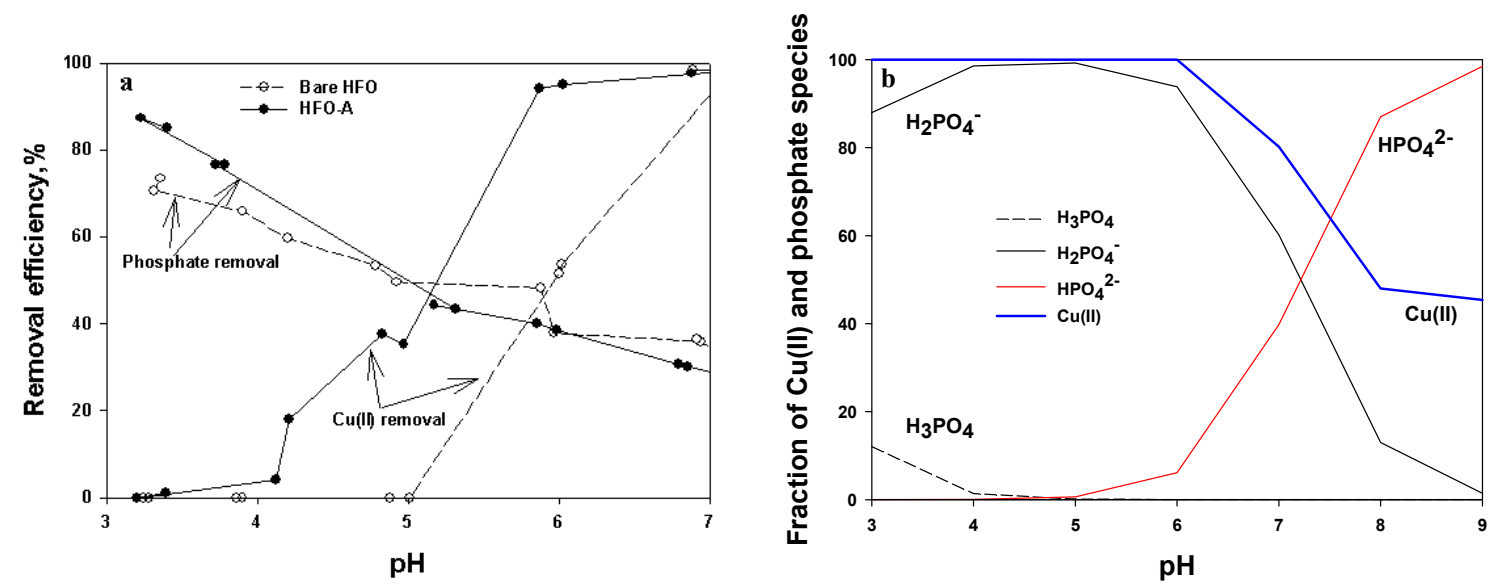

Figure 6. $\mathrm{Cu}(\mathrm{II})$ and phosphate removal efficiency, \% (a) and the fraction of $\mathrm{Cu}(\mathrm{II})$ and phosphate species as a function of initial $\mathrm{pH}(\mathbf{b})$.

In terms of phosphate removal, the trend is opposite to $\mathrm{Cu}(\mathrm{II})$ where efficiency clearly decreases with increasing $\mathrm{pH}$, indicating lower $\mathrm{pH}$ favors phosphate sorption. In general, phosphate speciation ( $\mathrm{pK}_{\mathrm{a}}$ values: $2.12,7.21$, and 12.67) and the surface charge of the adsorbent was determined by the solution $\mathrm{pH}$ presented by the point of zero charge (PZC), which has been previously reported to be 6.7 to 8.6 [54]. In the experimentally tested $\mathrm{pH}$ range, phosphate species (Figure 6b) was negatively charged, while the surface of the FHO was generally positively charged. This indicates that electrostatic interactions are possible. Consequently, it is proposed that the deprotonated carboxyl group on alginate led to the interaction with $\mathrm{Cu}(\mathrm{II})$, and the surface charge of FHO participated in phosphate removal.

\section{Conclusions}

A hybrid adsorbent based on iron hydroxide particles coated with alginate was developed using a simple synthesis process and these systems were applied for the removal of $\mathrm{Cu}(\mathrm{II})$ and phosphate from the solution. The selectivity and capacity for the novel adsorbent was confirmed through a series of batch equilibrium tests. This study revealed that FHO-A can serve to simultaneously remove both cation $(\mathrm{Cu}(\mathrm{II}))$ and anion (phosphate) species, a unique feature of this system. Our results found that the presence of alginate and $\mathrm{FHO}$ independently removed $\mathrm{Cu}(\mathrm{II})$ and phosphate, respectively, and both $\mathrm{Cu}$ (II) and phosphate were adsorbed onto FHO-A at the same time, but they did not interfere with the adsorption capacity of each other. The FTIR peak shifted before and after $\mathrm{Cu}(\mathrm{II})$ and phosphate adsorption, which indicated that electrostatic interactions happened. The equilibrium for sorption of $\mathrm{Cu}$ (II) was reached within $5 \mathrm{~min}$, demonstrating that the FHO-A were present as nanoparticles and the adsorption rate for $\mathrm{Cu}$ (II) was faster than phosphate. This is because phosphate molecules need to penetrate the alginate layer to reach the FHO surface. Based on sorption kinetics modeling, the pseudo 2nd and psedo 1st order have a strong correlation for $\mathrm{Cu}(\mathrm{II})$ and phosphate, respectively, because of the lay of alginate on the FHO surface. Compared with isotherm models, Langmuir and 
Freundlich with non-linear and linear derivations, the Freundlich model achieved the better fit. Finally, $\mathrm{Cu}$ (II) removal increased with the higher $\mathrm{pH}$ due to the alginate deprotonation, while the removal efficiency of phosphate increased with lower $\mathrm{pH}$ due to the surface charges on FHO.

Supplementary Materials: The following are available online at http:/www.mdpi.com/2076-3417/9/18/3835/s1, Figure S1: Plots of (a) Pseudo 1st order, (b) 2nd order and (c) intraparticle kinetic models.

Author Contributions: H.-G.K. and B.A. have conceptualized this work, conducted the experiments, and written draft. F.H. and B.A. have developed and interpreted the results.

Funding: This research was supported by Basic Science Research Program through the National Research Foundation of Korea (NRF) funded by the Ministry of Education (No. 2016R1D1A1B03930265).

Conflicts of Interest: The authors declare no conflicts of interest.

\section{References}

1. Wilde, E.W.; Benemann, J.R. Bioremoval of heavy-metals by the use of microalgae. Biotechnol. Adv. 1993, 11, 781-812. [CrossRef]

2. An, B.; Son, H.; Chung, J.; Choi, J.W.; Lee, S.H.; Hong, S.W. Calcium and hydrogen effects during sorption of copper onto an alginate-based ion exchanger: Batch and fixed-bed column studies. Chem. Eng. J. 2013, 232, 51-58. [CrossRef]

3. Paulino, A.T.; Minasse, F.A.S.; Guilherme, M.R.; Reis, A.V.; Muniz, E.C.; Nozaki, J. Novel adsorbent based on silkworm chrysalides for removal of heavy metals from wastewaters. J. Colloid Interface Sci. 2006, 301, 479-487. [CrossRef] [PubMed]

4. Barakat, M.A. New trends in removing heavy metals from industrial wastewater. Arab. J. Chem. 2011, 4, 361-377. [CrossRef]

5. Scheinost, A.C.; Abend, S.; Pandya, K.I.; Sparks, D. Kinetic controls on $\mathrm{Cu}$ and Pb sorption by ferrihydrite. Environ. Sci. Technol. 2001, 35, 1090-1096. [CrossRef] [PubMed]

6. Espana, J.S.; Pamo, E.L.; Pastor, E.S.; Andres, J.R.; Rubi, J.A.M. The removal of dissolved metals by hydroxysulphate precipitates during oxidation and neutralization of acid mine waters. Aquat. Geochem. 2006, 12, 269-298. [CrossRef]

7. Lin, L.C.; Juang, R.S. Ion-exchange kinetics of $\mathrm{Cu}$ (II) and $\mathrm{Zn}$ (II) from aqueous solutions with two chelating resins. Chem. Eng. J. 2007, 132, 205-213. [CrossRef]

8. Ariffin, N.; Abdullah, M.M.A.B.; Zainol, M.R.R.M.A.; Murshed, M.F.; Zain, H.; Faris, M.A.; Bayuaji, R. Review on adsorption of heavy metal in wastewater by using geopolymer. MATEC Web Conf. EDP Sci. 2017, 97, 01023. [CrossRef]

9. Fu, F.; Wang, Q. Removal of heavy metal ions from wastewaters: A review. J. Environ. Manage. 2011, 92, 407-418. [CrossRef]

10. Anastopoulos, L.; Kyzas, G.Z. Progress in batch biosorption of heavy metals onto algae. J. Mol. Liq. 2015, 209, 77-86. [CrossRef]

11. Lagoa, R.; Rodrigues, J.R. Kinetic analysis of metal uptake by dry and gel alginate particles. Biochem. Eng. J. 2009, 46, 320-326. [CrossRef]

12. Bhat, S.D.; Aminbhavi, T.M. Novel sodium alginate- $\mathrm{Na}^{+}$MMT hybrid composite membranes for pervaporation dehydration of isopropanol, 1,4-dioxane and tetrahydrofuran. Sep. Purif. Technol. 2006, 51, 85-94. [CrossRef]

13. Schoubbn, A.; Blasi, P.; Glovagnoli, S.; Rossi, C.; Ricci, M. Development of a salable procedure for fine calcium alginate particle preparation. Chem. Eng. J. 2010, 160, 63-369.

14. Lalley, J.; Han, C.; Li, X.; Dionysiou, D.; Mallikarjuna, N.; Nadagouda, M.N. Phosphate adsorption using modified iron oxide-based sorbents in lake water: Kinetics, equilibrium, and column tests. Chem. Eng. J. 2016, 284, 1386-1396. [CrossRef]

15. Saha, B.; Bains, R.; Greenwood, F. Physicochemical characterization of granular ferric fydroxide (GFH) for arsenic(V) sorption from water. Sep. Sci. Technol. 2005, 40, 2909-2932. [CrossRef]

16. Smith, E.; Ghiassi, K. Chromate removal by an iron sorbent: Mechanism and modeling. Water Environ. Res. 2006, 78, 84-93. [CrossRef] 
17. Zhou, L.; He, B.; Huang, J. One-step synthesis of robust amine- and vinyl-capped magnetic iron oxide nanoparticles for polymer grafting, dye adsorption, and catalysis. Appl. Mater. Interfaces 2013, 5, 8678-8685. [CrossRef]

18. Guo, X.; Chen, F. Removal of arsenic by bead cellulose loaded with iron oxyhydroxide from groundwater. Environ. Sci. Technol. 2005, 39, 6808-6818. [CrossRef]

19. Zouboulis, A.I.; Katsoyiannis, I.A. Arsenic removal using iron oxide loaded alginate beads. Ind. Eng. Chem. Res. 2002, 41, 6149-6155. [CrossRef]

20. An, B.; Lee, S.; Kim, H.G.; Zhao, D.; Park, J.; Choi, J.W. Organic/inorganic hybrid adsorbent for efficient phosphate removal from a reservoir affected by algae bloom. J. Ind. Eng. Chem. 2019, 69, 211-216. [CrossRef]

21. Magdy, Y.H.; Altaher, H. Kinetic analysis of the adsorption of dyes from high strength wastewater on cement kiln dust. J. Environ. Chem. Eng. 2018, 6, 834-841. [CrossRef]

22. An, B.; Zhao, D. Immobilization of As(III) in soil and groundwater using a new class of polysaccharide stabilized Fe-Mn oxide nanoparticles. J. Hazard. Mater. 2012, 211, 332-341. [CrossRef]

23. Arief, V.O.; Trilestari, K.; Sunarso, J.; Indrasati, N.; Ismadji, S. Recent Progress on biosorption of heavy metals from liquids using low cost biosorbents: Characterization, biosorption parameters and mechanism studies. Clean Soil Air Water 2008, 36, 937-982. [CrossRef]

24. Rahman, M.M.; Khan, S.B.; Jamal, A.; Faisal, M.; Aisiri, A.M. Iron oxide nanoparticles. In Nanomaterials; Rahman, M., Ed.; IntechOpen: London, UK, 2011; pp. 43-66.

25. Bumajdad, A.; Ali, S.; Mathew, A. Characterization of iron hydroxide/oxide nanaoparticles prepared in microemulsions stabilized with cationic/non-ionic surfactant mixtures. J. Colloid Interface Sci. 2011, 355, 282-292. [CrossRef]

26. Sakugawa, K.; Ikeda, A.; Takemura, A.; Ono, H. Simplified method for estimation of composition of alginates by FTIR. J. Appl. Polym. Sci. 2004, 93, 1372-1377. [CrossRef]

27. Helmiyati; Aprilliza, M. Characterization and properties of sodium alginate from brown algae used as an ecofriendly superabsorbent. IOP Conf. Ser. Mater. Sci. Eng. 2017, 188, 1.

28. Li, Y.; Liu, F.; Xia, B.; Du, Q.; Zhang, P.; Wang, D.; Wang, Z.; Xia, Y. Removal of copper from aqueous solution by carbon nanotube/calcium alginate composites. J. Hazard. Mater. 2010, 177, 876-880. [CrossRef]

29. Papageorgiou, S.K.; Kouvelos, E.P.; Favvas, E.; Sapalidis, A.A.; Romanos, G.E.; Katsaros, F.K. Metal-carboxylate interactions in metal-alginate complex studied with FTIR spectroscopy. Carbhyd. Res. 2010, 345, 469-473. [CrossRef]

30. Filipiuk, D.; Fuks, L.; Majdan, M. Transition metal complexes with uronic acids. J. Mol. Struct. 2005, 744, 705-709. [CrossRef]

31. Fuks, L.; Filipiuk, D.; Majdan, M. Transition metal complexes with alginate biosorbent. J. Mol. Struct. 2006, 792, 104-109. [CrossRef]

32. Sigg, L.; Stumm, W. The interaction of anions and weak acids with the hydrous goethite $(\alpha-\mathrm{FeOOH})$ surface. Colloids Surf. 1981, 2, 101-117. [CrossRef]

33. Goldberg, S.; Sposito, G. A chemical model of phosphate adsorption by soils: I. Reference oxide minerals. Soil Sci. Am. J. 1984, 48, 772-783. [CrossRef]

34. Persson, P.; Nilsson, N.; SJöberg, S. Structure and bonding of orthophosphate ions at the iron oxide-aqueous interface. J. Colloid Interface Sci. 1996, 177, 263-275. [CrossRef]

35. Mahmoodi, N.M. Equilibrium, kinetics, and thermodynamics of dye removal using Alginate in binary systems. J. Chem. Eng. Data 2011, 56, 2802-2811. [CrossRef]

36. Deliyanni, E.A.; Peleka, E.N.; Lazaridis, N.K. Comparative study of phosphates removal from aqueous solutions by nanocrystalline akaganeite and hybrid surfactant-akaganeite. Sep. Purif. Technol. 2007, 52, 478-486. [CrossRef]

37. Pan, B.; Wu, J.; Pan, B.; Lu, L.; Zhang, W.; Xiao, L.; Wang, X.; Tao, X.; Zheng, S. Development of polymer-based nanosized hydrated ferric oxides (HFOs) for enhanced phosphate removal from waste effluents. Water Res. 2009, 43, 4421-4429. [CrossRef]

38. Zhang, G.; Liu, H.; Liu, R.; Qu, J. Removal of phosphate from water by a Fe-Mn binary oxide adsorbent. J. Colloid Interface Sci. 2009, 335, 168-174. [CrossRef]

39. Bayramoglu, G.; Arica, M.Y. Construction a hybrid biosorbent using scenedesmus quadricauda and Ca-alginate for biosorption of $\mathrm{Cu}(\mathrm{II}), \mathrm{Zn}(\mathrm{II})$ and $\mathrm{Ni}(\mathrm{II})$ : Kinetics and equilibrium studies. Bioresour. Technol. 2009, 100, 186-193. [CrossRef] 
40. Ho, Y.S.; McKay, G. The kinetics of sorption of divalent metal ions onto sphagnum moss peat. Water Res. 2000, 34, 735-742. [CrossRef]

41. Dursun, A.Z. A comparative study on determination of the equilibrium, kinetic and thermodynamic parameters of biosorption of copper(II) and lead(II) ions onto pretreated aspergillus niger. Biochem. Eng. J. 2006, 28, 187-195. [CrossRef]

42. Weber, W.J.; Morris, J.C. Kinetics of adsorption on carbon from solution. J. Sanit. Eng. Div. ASCE 1963, 89, 31-59.

43. Aroua, M.K.; Yin, C.Y.; Lim, F.N.; Kan, W.L.; Daud, W.M.A. Effect of impregnation of activated carbon with chelating polymer on adsorption kinetics of $\mathrm{Pb}^{2+}$. J. Hazard. Mater. 2009, 166, 1526-1529. [CrossRef]

44. Hameed, B.H.; Tan, I.A.W.; Ahmad, A.L. Adsorption isotherm, kinetic modeling and mechanism of 2,4,6-trichlorophenol on coconut husk-based activated carbon. Chem. Eng. J. 2008, 144, 235-244. [CrossRef]

45. Tempkin, M.I.; Pyzhev, V. Kinetics of ammonia synthesis on promoted iron catalyst. Acta Phys. Chim. USSR 1940, 12, 327-356.

46. Toth, J. State equations of the solid gas interface layer. Acta Chem. Acad. Hung. 1971, 69, 311-317.

47. Redlich, O.; Peterson, D.L. A useful adsorption isotherm. J. Phys. Chem. 1959, 63, 1024-1026. [CrossRef]

48. Dubinin, M.M.; Radushkevich, L.V. The equation of the characteristic curve of the activated charcoal. Proc. Acad. Sci. USSR Phys. Chem. Sect. 1947, 55, 331-337.

49. Langmuir, I. The constitution and fundamental properties of solids and liquids. J. Am. Chem. Soc. 1916, 38, 2221-2295. [CrossRef]

50. Freundlich, H.M.F. Over the adsorption in solution. J. Phys. Chem. 1906, 57, 385-471.

51. Kargi, F.; Cikla, S. Biosorption of zinc(II) ions onto powdered waste sludge (PWS): Kinetics and isotherms. Enzyme Microb. Technol. 2006, 38, 705-710. [CrossRef]

52. An, B.; Lee, H.; Lee, S.; Lee, S.H.; Choi, J.W. Determining the selectivity of divalent metal cations for the carboxyl group of alginate hydrogel beads during competitive sorption. J. Hazard. Mater. 2015, 298, 11-18. [CrossRef]

53. Onsøyen, E. Alginates. In Thickening and Gelling Agents for Food; Imeson, A., Ed.; Springer: Boston, MA, USA, 1997; pp. 22-44.

54. Parks, G.A.; de Bruyn, P.L. PZC of iron oxide. J. Phys. Chem. 1962, 66, 967-973. [CrossRef] 